\title{
Study Outcome Measurement
}

National Cancer Institute

\section{Source}

National Cancer Institute. Study Outcome Measurement. NCI Thesaurus. Code C93407.

Specific key measurement(s) or observation(s) used to measure the effect of experimental variables on the subjects in a study, or for observational studies, to describe patterns of diseases or traits or associations with exposures, risk factors or treatment. The specific measure that receives the most emphasis in assessment. 